\title{
CORRELATION BETWEEN HEMOGLOBIN A1C IN DIABETIC PATIENTS WITH RATE OF INFECTION AND WOUND COMPLICATIONS FOLLOWING DECOMPRESSIVE SPINE SURGERY
}

\author{
Saadi Abdulsalam Abdullah ${ }^{*}$, Raqib S Tato ${ }^{\circledR}$ \& Muzahem M Taha\# \\ ${ }^{*} \mathrm{MB}, \mathrm{ChB}$, Ministry of Health, West Erbil Emergency Hospital, Neurosurgery Department. ${ }^{\circledR} \mathrm{MB}, \mathrm{ChB}$, \\ MS Iran, Consultant Neurosurgeon, West Emergency Hospital, Neurosurgery Department, Erbil, IRAQ. \\ ${ }^{\#}$ MB,ChB, FICS, Kirkuk University, College of Medicine, Sardam Private Hospital, Consultant \\ Orthopedic Spine Surgeon, Kirkuk, IRAQ.
}

\begin{abstract}
Diabetes mellitus (DM) is known as an important risk factor for surgical site infection (SSI) in spine surgery. A chronic state of impaired glucose metabolism affects multiple components of the immune system, possibly leading to an increased incidence of post-operative infection. Such infection increases morbidity, length of stay, and overall cost. The present study was designed to assess the correlation between pre-operative hemoglobin A1c ( $\mathrm{HbA1c}$ ) and the incidence of post-operative infection in surgical patients undergoing decomperssive spine operations.

Forty diabetic patients who underwent decompressive spine surgery at different levels of spine were included in this retrospective study. These include 23 females and 17 males with mean age of 57.5 years. The patients data were collected from hospitals and private clinics archives including value of preoperative hemoglobin $\mathrm{A} 1 \mathrm{c}$, random blood sugar, postoperative $\mathrm{C}$ reactive protein (CRP) and white blood cells count (WBC) as a diagnostic laboratory tests for identification of postoperative infection in follow-up periods.

The overall rate of infection in our study was $12.5 \%$, which was categorized into 2 groups (Uncontrolled diabetes hemoglobin A1c $>7$ and controlled hemoglobin A1C $\leq 7$ ), so the rate of infection was $19.2 \%$ among patients with uncontrolled diabetes compared with $0 \%$ among patients with controlled diabetes $(p=0.143)$. The mean hemoglobin $A 1 c$ among patients with uncontrolled diabetes who developed infection was $9.72 \%$ compared with $7.34 \%$ among those with no infection $(p<0.001)$

In conclusion, diabetic patients whose blood glucose levels were poorly controlled before surgery as indicated by high hemoglobin A1c were at high risk for postoperative wound infection. Preoperative hemoglobin A1c above $7.34 \%$ could serve as a threshold value for significant increased risk of postoperative surgical site infection.

Key words: Diabetes Mellitus, HbA1C, decompressive spine surgery, infection, complications.
\end{abstract}

Introduction

$\mathrm{D}$

iabetes mellitus is a disease of blood glucose dysregulation that is known to cause complications of the microvasculature often leading to cardiovascular, ophthalmic, renal and peripheral vascular disease ${ }^{1}$. The Center for Disease Control and Prevention provides updated statistics about diabetes in United States for audience stated that 30.3 million people have diabetes $(9.4 \%$ of the US population), 23.1 million people are diagnosed while 7.2 million peoples are undiagnosed ${ }^{2}$.

Diabetes impairs wound healing and predispose to wound infection in spine and other surgical sites. Postoperative wound infection have been reported to occur up to $24 \%$ of diabetic patients undergoing spine surgery. The mechanism by which diabetes is thought to contribute to infection risk included; increased glucose concentration in wound 
fluid, the presence of dysfunctional polymorphonuclear neutrophils \& macrophages, impaired lymphocyte chemotaxis, and delayed wound reepithelialization ${ }^{3}$.

Surgical site infection (SSI) is a relatively common complication after spinal surgery. Surgical site infection increases the morbidity, mortality, length of hospital stay, re-admissions, and healthcare costs. Factors known to affect the risk of surgical site infection includes: age, ASA score, obesity, diabetes mellitus, smoking, previous surgeries, previous infections, previous radiation therapy, chronic skin conditions, and how closely the patient adheres to postoperative wound care instructions ${ }^{4-9}$. Surgery-related risk factors includes; the type of surgical approach, the use of instrumentation, bone graft harvesting, estimated blood loss, and time of surgery ${ }^{10}$.

For patients with diabetes mellitus undergoing any surgical intervention, it is generally thought that maintaining tight glycemic control in the perioperative period might reduce the risk of complications. For instance, the association between tightly controlled perioperative various glycemic markers, such as the glycated hemoglobin Alc level, has been associated with decreased infectious complications following total joint arthroplasty in the broader orthopedic literature. The hemoglobin A1c level represents an easily obtainable and objective lab value that reflects a patient's glycemic status over a 2-3 month period $^{11}$.

The present study was designed to assess the correlation between pre-operative hemoglobin A1c and the incidence of post-operative infection in surgical patients undergoing decomperssive spine surgery. All our patients have diabetes and were diagnosed by internist. Our hypotheses was to good managing diabetics as close to a normal blood glucose level safely, this means levels between 70 to $130 \mathrm{mg} / \mathrm{dl}$ before meals and less than $180 \mathrm{mg} / \mathrm{dl}$ two hours after starting meal, with an HbAlc less than $7 \%$. Another aim of the current study is to calculate a threshold level of hemoglobin A1c above which the risk of postoperative infection after decompressive spine surgery that increases significantly in patients with diabetes.

\section{Patients and Methods}

In the present retrospective study, a total of 40 diabetic patients were selected from both Erbil West Emergency Hospital and Sardam Private Hospital, who underwent decompressive spine surgeries which included various surgical procedures like laminectomies, laminotomies, foraminotomies, and falavectomies for different pathologies like disc herniation, spinal stenosis and etc. These techniques were performed in different regions of the spine like lumber, dorsal and cervical. Reviews of our cases started from January 2017 to November 2018 with different follow-up time.

All our patients had history of diabetes mellitus or were diagnosed by internist that carrying diabetes mellitus with variety of modalities of treatment either on oral hypoglycemic agents or insulin.

Patients age less than 18 years, or who had treated with spine fixation surgeries for different pathologies, or other immunosuppressant diseases were excluded from the study.

Third generation cephalosporin was administered intravenously 30 minutes before starting surgery, and postoperative intravenous antibiotics were orderd for five days. All patients with diabetes mellitus received subcutaneous insulin at postoperative period aiming to lower blood glucose to less than $200 \mathrm{mg} / \mathrm{dl}$.

Our data were collected from hospital and clinic archives with different follow-up schedules, these data included; age, gender, approximate time for surgery which is divided into less than 2 hours or 
more than 2 hours, region of spine surgery, and number of spine levels.

Regarding laboratories tests, we used the last hemoglobin A1c and random blood sugar at the day before surgery, although for evidence of infection we used Creactive protein and white blood cells count as laboratory markers at postoperative follow-up period.

Surgical site infection was diagnosed using the Center for Disease Control and Prevention (CDC) definition and guidelines, Surgical site infection included superficial surgical site infections that occurred within 30 days and deep surgical site and organ space infections that occurred within 30-90 days postoperatively.

Data were analyzed using the Statistical Package for Social Sciences (SPSS, version 22). Chi square test of association was used to compare proportions. Fisher's exact test was used when the expected count of more than $20 \%$ of the cells of the table was less than 5 . Student's $t$ test of two independent samples was used to compare the two means. A p-value of $\leq 0.05$ was considered as statistically significant.
The ethical approval of the present study was obtained from the Kurdistan Board for Medical Specialties. Informed consent was obtained from all the patients prior to study and they were asked to permit the review of their records.

\section{Results}

Forty diabetic patients underwent decompressive spine surgery. Fourteen patients had controlled diabetes (group I) and the rest (26) had uncontrolled diabetes (group II). Their mean age was $57.58 \pm 10.58$ years, ranging from 38 to 78 years. The median was 59 years. The highest proportion $(37.5 \%)$ of the patients aged $60-69$ years, and only $12 \%$ aged $\geq 70$ years. No significant difference in age distribution was found between patients with controlled diabetes and patients with uncontrolled diabetes $(p=0.964)$. More than half $(57.5 \%)$ of the patients were females. No significant differences were detected between the two groups regarding the gender distribution $(p=0.169)$. The majority underwent the operation in Sardam Private Hospital as presented in Table I.

Table I. Basic characteristics of the studied sample.

\begin{tabular}{|c|c|c|c|c|c|c|c|}
\hline & \multicolumn{2}{|c|}{ Controlled DM } & \multicolumn{2}{|c|}{ Uncontrolled DM } & \multicolumn{2}{|c|}{ Total } & \multirow[t]{2}{*}{$P$ value } \\
\hline & No. & $(\%)$ & No. & $(\%)$ & No. & $(\%)$ & \\
\hline \multicolumn{8}{|l|}{ Age (years) } \\
\hline$<50$ & 4 & $(28.6)$ & 7 & (26.9) & 11 & $(27.5)$ & \\
\hline $50-59$ & 3 & (21.4) & 6 & $(23.1)$ & 9 & $(22.5)$ & \\
\hline $60-69$ & 6 & (42.9) & 9 & $(34.6)$ & 15 & $(37.5)$ & \\
\hline$\geq 70$ & 1 & $(7.1)$ & 4 & (15.4) & 5 & $(12.5)$ & $0.964 *$ \\
\hline \multicolumn{8}{|l|}{ Gender } \\
\hline Male & 8 & $(57.1)$ & 9 & $(34.6)$ & 17 & $(42.5)$ & \\
\hline Female & 6 & (42.9) & 17 & $(65.4)$ & 23 & $(57.5)$ & 0.169 \\
\hline \multicolumn{8}{|l|}{ Center } \\
\hline $\begin{array}{l}\text { West Erbil } \\
\text { emergency hospital }\end{array}$ & 2 & $(14.3)$ & 6 & $(23.1)$ & 8 & $(20.0)$ & \\
\hline $\begin{array}{l}\text { Sardam } \\
\text { hospital }\end{array}$ & 12 & $(85.7)$ & 20 & $(76.9)$ & 32 & $(80.0)$ & $0.689^{*}$ \\
\hline Total & 14 & $(100.0)$ & 26 & $(100.0)$ & 40 & $(100.0)$ & \\
\hline
\end{tabular}

*By Fisher's exact test. 
Table II shows that the level of surgery was in the lumber region in $77.5 \%, 15 \%$ in the cervical region, and $7.5 \%$ in the dorsal region, with no significant difference between the two groups $(p=0.836)$. The operation involved multiple levels in half of the patients
(35.7\% in controlled, and $57.7 \%$ in the uncontrolled diabetes, but the difference was not significant, $p=0.440$ ). The length of surgery was $\geq 2$ hours in $15.4 \%$ of patients with uncontrolled diabetes compared with $0 \%$ among patients with controlled diabetes $(\mathrm{p}=0.278)$.

Table II: Details of the operations

\begin{tabular}{|c|c|c|c|c|c|c|c|}
\hline & \multicolumn{2}{|c|}{ Controlled DM } & \multicolumn{2}{|c|}{ Uncontrolled DM } & \multicolumn{2}{|c|}{ Total } & \multirow[t]{2}{*}{$P$ value } \\
\hline & No. & $(\%)$ & No. & $(\%)$ & No. & $(\%)$ & \\
\hline \multicolumn{8}{|c|}{ Level of surgery } \\
\hline Lumber & 10 & (71.4) & 21 & $(80.8)$ & 31 & $(77.5)$ & \\
\hline Cervical & 3 & (21.4) & 3 & (11.5) & 6 & $(15.0)$ & \\
\hline Dorsal & 1 & $(7.1)$ & 2 & $(7.7)$ & 3 & $(7.5)$ & $0.836^{*}$ \\
\hline \multicolumn{8}{|c|}{ Number of levels } \\
\hline Single & 6 & (42.9) & 8 & $(30.8)$ & 14 & $(35.0)$ & \\
\hline Two levels & 3 & (21.4) & 3 & (11.5) & 6 & $(15.0)$ & \\
\hline Multiple & 5 & $(35.7)$ & 15 & $(57.7)$ & 20 & $(50.0)$ & $0.440 *$ \\
\hline \multicolumn{8}{|c|}{ Length of surgery } \\
\hline$<2$ hours & 14 & $(100.0)$ & 22 & (84.6) & 36 & $(90.0)$ & \\
\hline$\geq 2$ hours & 0 & $(0.0)$ & 4 & $(15.4)$ & 4 & $(10.0)$ & $0.278^{*}$ \\
\hline Total & 14 & $(100.0)$ & 26 & $(100.0)$ & 40 & $(100.0)$ & \\
\hline
\end{tabular}

*By Fisher's exact test.

Table III shows that the C-reactive protein was positive among $26.9 \%$ of patients with uncontrolled diabetes compared with $0 \%$ among patients with controlled diabetes, but the difference was not significant $(\mathrm{p}=0.075)$. The rate of infection was $19.2 \%$ among patients with uncontrolled diabetes compared with $0 \%$ among patients with controlled diabetes $(\mathrm{p}=0.143)$.

Table III: Post-operative outcome

\begin{tabular}{lllllllll}
\hline & \multicolumn{2}{c}{ Controlled DM } & \multicolumn{2}{c}{ Uncontrolled DM } & \multicolumn{2}{c}{ Total } & P value \\
\cline { 2 - 6 } & No. & $(\%)$ & No. & $(\%$ & No. & $(\%)$ & \\
\hline CRP & & & & & & & \\
Negative & 14 & $(100.0)$ & 19 & $(73.1)$ & 33 & $(82.5)$ & \\
Positive & 0 & $(0.0)$ & 7 & $(26.9)$ & 7 & $(17.5)$ & $0.075^{*}$ \\
Infection & & & & & & & \\
No & 14 & $(100.0)$ & 21 & $(80.8)$ & 35 & $(87.5)$ & \\
Yes & 0 & $(0.0)$ & 5 & $(19.2)$ & 5 & $(12.5)$ & $0.143^{*}$ \\
\hline Total & 14 & $(100.0)$ & 26 & $(100.0)$ & 40 & $(100.0)$ & \\
\hline
\end{tabular}

*By Fisher's exact test.

The mean hemoglobin Alc among patients with uncontrolled diabetes who developed infection was $9.72 \%$ compared with 7.34\% among those with no infection $(\mathrm{p}<0.001)$ as presented in figure 1. 


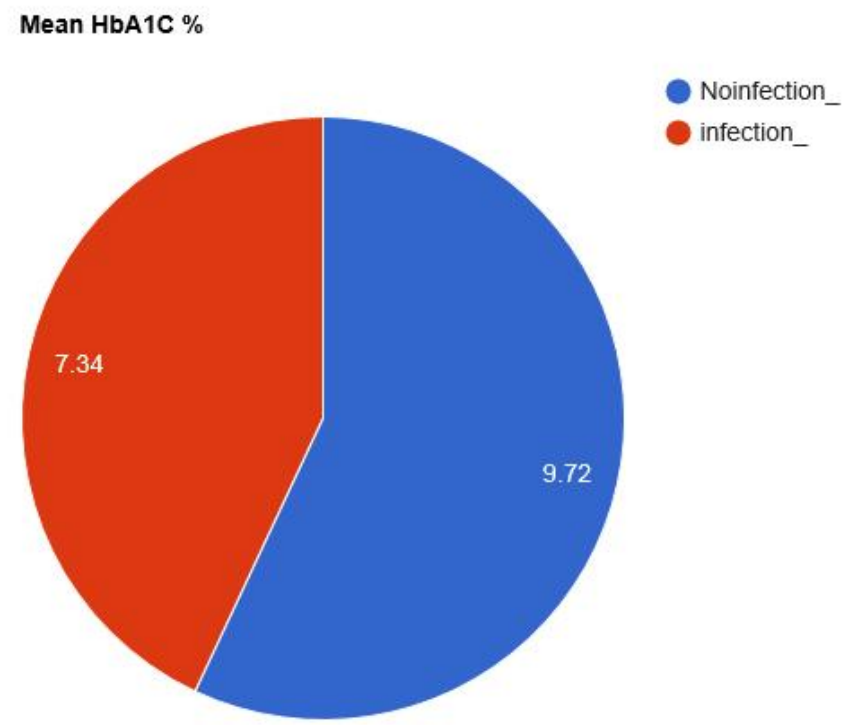

Figure 1: Mean of $\mathrm{HbA1C}$ by infection status among patients with uncontrolled diabetes. $\mathrm{P}<0.001$

\section{Discussion}

Many studies reported that diabetes is a risk factor for development of wound infection after spinal surgery, although there are only few articles showed correlation between hemoglobin A1c and rate of infection in diabetic patients following spinal procedures.

In our study hemoglobin A1c $>7 \%$ have been acceptable as a cutoff point for uncontrolled diabetes and value of $\leq 7 \%$ as controlled diabetic patients.

Reported surgical site infections rates ranged from less than $1 \%$ to more than $10 \%$, depending on the diagnosis and surgery-related or patient factors ${ }^{11}$. In our study, the rate of infection was was $12.5 \%$ as compared with Hikata and colleagues $^{10}$ who investigated relationship between perioperative hemoglobin A1c levels and surgical site infection following posterior thoracic and lumbar spinal fusion (retrospective study of 435 patients and 36 of them had diabetes mellitus), their rate of infection was $16.7 \%$. Another study by Jourdan and colleagues ${ }^{11}$ which determine hemoglobinA1c level as a predictor of deep infection after single lumber level decompression surgery in diabetic patients, overall rate of postoperative infection ranged from $0.5 \%$ to $3.5 \%$.

In our study preoperative hemoglobin A1c was above $7.34 \%$ that could be serve as threshold value in which the infection developed following decompressive spine surgery, while the threshold value for two above mentioned reports ${ }^{10,11}$ were $7.5 \%$ and $<7 \%$ respectively.

Klemencsic and colleagues ${ }^{12}$ published a paper regarding risk factor for surgical site infection after elective lumber surgeries, they found aging could be a risk factor for SSI specially after age of 54 year and explained it by general health state and systemic immunoreactivity declining, in our study the median age was 59 year and no significant difference between age distribution and surgical site infections $(\mathrm{p}=0.964)$.

$\mathrm{Kim}$ and colleagues ${ }^{13}$ found the association between prolonged surgery and postoperative surgical site infection, they analyzed 1831 patients who had posterior lumber interbody fusion, and found that surgical site infections patients had longer surgery than those in the non- 
surgical site infections group $(\mathrm{p}=0.008)$, however in another case control study by Petilon $^{14}$ who found a negative relationship $(p=0298)$, similarly our results was negative $(\mathrm{p}=0.278)$.

This study had some limitations regarding the sample size, a larger data should be conducted to confirm our finding.
Conclusion; Diabetic patients whose blood glucose levels were poorly controlled before surgery were at risk for postoperative wound infection. To prevent this complication in diabetic patients, we recommend lowering the Hemoglobin A1c to $7.34 \%$ before performing spine surgery.

\section{References}

1. Javier Z. Guzman, James C. Iatridis, Branko Skovlj, Holt Cutler. Outcomes and complications of Diabetes Mellitus on patients undergoing degenerative lumber spine surgery. Spine (Phila Pa 1976). 2014 Sep 1; 39(19): 1596-1604.

2. National diabetes statistical report 2017. http://www.cdc.gov/diabetes /data/statistics/ statistics-report.html.

3.Yomans and Winn Neurological surgery, Seventh edition, chapter 37, Postoperative infection of the spine. Elsevier 2016.

4. Schuster JM, Rechtine G, Norvell DC, Dettori JR. The influence of perioperative risk factors and therapeutic interventions on infection rates after spine surgery: a systematic review. Spine. 2010;35:S125-137.

5. Apisarnthanarak A, Jones M, Waterman BM, Carroll CM, Bernardi R, Fraser VJ. Risk factors for spinal surgical-site infections in a community hospital: a case-control study. Inf Cont Hosp Epidemiol. 2003;24:31-36.

6. Fang A, Hu SS, Endres N, Bradford DS. Risk factors for infection after spinal surgery.Spine (Phila Pa 1976). 2005;30:1460-1465.

7. Friedman ND, Sexton DJ, Connelly SM, Kaye KS. Risk factors for surgical site infection complicating laminectomy.Inf Cont Hosp Epidemiol. 2007;28:1060-5.

8. Kanafani ZA, Dakdouki GK, El-Dbouni O, Bawwab T, Kanj SS. Surgical site infections following spinal surgery at a tertiary care center in Lebanon: incidence, microbiology, and risk factors. Scand J Inf Dis. 2006;38:589-592.

9. Klekamp J, Spengler DM, McNamara MJ, Haas DW. Risk factors associated with methicillin-resistant staphylococcal wound infection after spinal surgery. J Spinal Disord. 1999;12:187-191

10. Tomohiro Hikata, Akio Iwanami, Naobumi Hosogane, Kota Watanabe, Ken Ishii, Masaya Nakamura, Michihiro Kamata, Yoshiaki Toyama, Morio Matsumoto. High preoperative hemoglobin A1c is a risk factor for surgical site infection after posterior thoracic and lumbar spinal instrumentation surgery. Journal of Orthopaedic Science, 2014, Vol. 19(2); 223-228.

11. Jourdan M. Cancienne, Brian C. Werner, Dennis Q. Chen, Hamid Hassanzadeh, Adam L. Shimer. Perioperative hemoglobin A1c as a predictor of deep infection following single level lumbar decompression in patients with diabetes. Spine 2017.

12-Klemencsics I, Lazary A, Szoverfi Z, Bozsodi A, Eltes P, Varga PP. Risk factors for surgical site infection in elective routine degenerative lumbar surgeries. Spine 2016;16:1377-1383.

13- Kim JH, Ahn DK, Kim JW, Kim GW. Particular Features of Surgical Site Infection in Posterior Lumbar Interbody Fusion. Clin. Orthop. Surg. 2015;7(3):337-343.

14- Petilon JM, Glassman SD, Dimar JR, Carreon LY. Clinical outcomes after lumbar fusion complicated by deep wound infection: a case-control study. Spine. 2012; 37(16):1370-1374. 